\title{
Things have to get better ${ }^{\dagger}$
}

\author{
David Storer
}

The feelings and opinions of consultants who retired earlier than they needed to (Kendell \& Pearce, 1997) do not make festive reading and will sadden, but not surprise, most psychiatrists.

The comments quoted at the end of the paper are typical of those heard from colleagues, not only psychiatrists, on a daily basis. It is difficult to know which are the most telling: "Persistent awareness of a disaster about to happen", "fatuous form filling". "I was no longer able to practise psychiatry properly", or "nothing will induce me to return".

More surprising is the finding that $33 \%$ had retired before the age of 55 (11\% before 45$)$ and that only $36 \%$ had waited until they had a $40 / 80$ pension. One explanation of the increase in early retirement is that this only reflects a similar general trend across all occupations. However, the substantial number retiring before 55 does appear to indicate a particular desperation to leave psychiatry.

This group of psychiatrists are, of course, likely to have comprised the more disillusioned end of the spectrum and it could be argued that a control group of consultants (who have not retired) matched for age would show a different response. Nevertheless this group represents a substantial loss from the consultant body and we know from our own experiences that these feelings are not atypical.

Kendell \& Pearce suggest some ways in which the retirement rate can be slowed down, but they also comment that the infusion of new blood is insufficient to replace the haemorrhage. The level of consultant vacancies, as identified by the College census, is indeed such that the annual output of Certificate of Completion of Specialist Training holders is less than that required even to fill current vacant posts, leaving no excess for new vacancies or consultant expansion. The response which we have made in the past, which is to use these data to argue for an expansion of higher training posts, is no longer effective as it now appears that we have enough posts to absorb all of those passing the membership examination and wanting to proceed to higher training.

\footnotetext{
'See pp. 741-745, this issue.
}

What should be our response (apart, that is, from buying maximum 'added years' and making extra pension contributions)? The answers may lie in this survey. There is little evidence from the replies that the respondents no longer enjoyed psychiatry, in fact many appear to be actively seeking out clinical work after retirement. Most colleagues I speak to, like myself, regard their out-patient clinic as the last refuge of sanity in the week's work. A time when the doctor-patient relationship is relatively intact and we can remind ourselves of why we chose to do psychiatry in the first place.

The reasons given for the wish to retire are largely organisational: increasing bureaucracy. Government policies, the internal market, interference by managers. Some would argue that the medical profession as a whole has been supine in allowing these factors to develop. There have been doctors who have embraced these changes with enthusiasm so that managers can always quote doctors who support them. It is sad that several respondents cite the activities of colleagues working as clinical or medical directors as a reason leading them to retire. Others would say that our College could have fought harder to resist such impositions as the Supervision Register and the bureaucratic excesses of the Care Programme Approach. However, we are where we are now and none of these processes are irreversible.

When asked what could have prevented their retirement some consultants replied "a change of Government". We now have that new Government and although there has been little perceptible change of attitudes at local level so far this must be the time to begin to fight back.

We will only succeed if we work as a united speciality. The census shows high consultant vacancy rates across all psychiatric specialities and it is not effective for us to maintain that our particular branch is the only one which is hardpressed. We will not succeed if we complain that the College is not doing enough. We, the Members and Fellows, are the College and although many may feel so overworked and stressed that they cannot play an active part in College affairs there is much that can be done at local level to reclaim ideals referred to by some of the respondents so that we have a more rewarding professional life and our patients can receive a higher standard of care. 


\section{EDITORIALS}

Ultimately we will only deal with our staffing crisis by persuading more young doctors to enter psychiatry. How can we do this with any sincerity if we cannot wait to leave the speciality ourselves? We owe it to our patients, future psychiatrists, and ourselves to move to the offensive in order to restore the enjoyment and satisfaction in practising the most fascinating of medical specialities.

\section{Reference}

Kendell. R. E. \& PEARCE, A. Consultant psychiatrists who retired prematurely in 1995 and 1996. Psychiatric Bulletin, 21, 741-745.

David Storer, Consultant Psychiatrist, General Infirmary at Leeds, Great George Street, Leeds, West Yorkshire LS29 3EX 